\title{
Quiz
}

\section{Mit Ingwer gegen Übelkeit}

Obgleich die Prophylaxe von akuter und verzögerter Emesis unter onkologischen Therapien heute Standard ist, und die meisten Patienten deutlich weniger Erbrechensepisoden erleben, leiden viele doch nach wie vor unter Übelkeit. Dass Ingwer bei Übelkeit verschiedenster Ursachen wohltuend wirkt, weiß man seit Langem. Allerdings ist nach wie vor nicht bekannt, welche Mechanismen dieser Wirkung genau zugrundeliegen. Einige der Puzzleteile konnten aber bereits identifiziert werden. Doris Berger

Welche der folgenden Aussagen ist durch Studien eindeutig widerlegt?

A Gingerol und Shogaol sind pharmakologisch aktive Inhaltsstoffe der Ingwerwurzel.

B Die antiemetische Wirkung von Ingwerberuht auch auf einer Modukation des 5-HT3-Rezeptors.

C Ingwer beeinflusst die Motilität des Darmes und wirkt nur dadurch gegen Übelkeit.

Der Buchstabe der richtigen Antwort ist

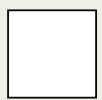

\section{Name}

Straße, Nr.

\section{PLZ, Ort}

Was ich noch sagen wollte ...

\section{Coupon bitte ausfüllen und abschicken an}

Springer Medizin, Urban \& Vogel GmbH

Redaktion Im Focus Onkologie - Quiz 9/2015

Aschauer Straße 30, 81549 München

Oder senden Sie uns eine E-Mail an doris.berger@springer.com

Einsendeschluss: 14.10.2015

\section{Und das können}

\section{Sie gewinnen ...}

Alles, was Wissen schafft.

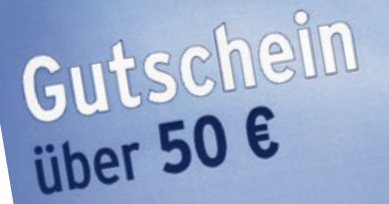

Q Springer Medizin

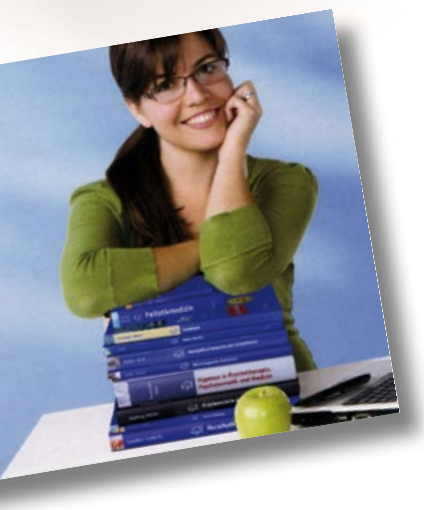

Unter den richtigen

Einsendungen verlosen

wir drei Gutscheine über

50 Euro, die Sie für ein

beliebiges Springer-Buch

einlösen können.

Einsendeschluss ist der

14.10.2015
Lösung des Quiz 6/2015 Richtig war: A

Die Gewinne gehen an:

Ch. Sorgenfrei, 21218 Seevetal-Waldesruh

H. List, 06124 Halle

R. Janker, 83646 Bad Tölz

Herzlichen Glückwunsch! 